\title{
Understanding the Influence of Eating Patterns on Binge Drinking: A Mediation Model
}

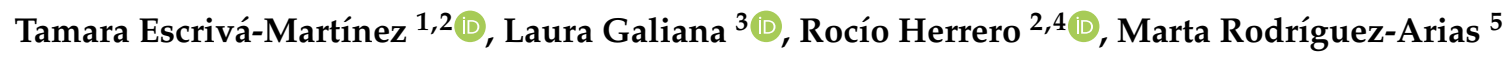 \\ and Rosa $M^{\mathrm{a}}$ Baños 1,2,4,*(D) \\ 1 Department of Personality, Evaluation and Psychological Treatment, Faculty of Psychology, University of Valencia, \\ 46010 Valencia, Spain; tamaraescrivamartinez@gmail.com \\ 2 Polibienestar Research Institute, University of Valencia, 46022 Valencia, Spain; ro.herrero.09@gmail.com \\ 3 Department of Methodology for the Behavioral Sciences, Faculty of Psychology, University of Valencia, \\ 46010 Valencia, Spain; laura.galiana@uv.es \\ 4 CIBERObn Physiopathology of Obesity and Nutrition, Instituto de Salud Carlos III, 28029 Madrid, Spain \\ 5 Department of Psychobiology, Faculty of Psychology, University of Valencia, 46010 Valencia, Spain; \\ marta.rodriguez@uv.es \\ * Correspondence: banos@uv.es
}

Received: 16 October 2020; Accepted: 14 December 2020; Published: 17 December 2020

\begin{abstract}
Background: Binge drinking is an important health problem, and it has been related to binge eating and fat intake in animal models, but this relationship has not been tested in humans. The first objective of this study was to analyze whether binge eating and fat intake are related to binge drinking in a youth sample. The second objective was to analyze whether binge eating and fat intake mediate the relationship between individual factors associated with binge eating and fat intake (sex, body mass index (BMI), drive for thinness, body dissatisfaction, eating styles, impulsivity, and food addiction) and binge drinking. Methods: A sample of 428 undergraduate students filled out several questionnaires on binge drinking, binge eating, fat intake, drive for thinness, body dissatisfaction, eating styles, food addiction, and impulsivity. Results: Results showed an excellent model fit: $\chi^{2}(25)=30.342(p=0.212)$, comparative fit index $(\mathrm{CFI})=0.992$, root mean squared error of approximation (RMSEA) $=0.022[90 \% \mathrm{CI}=0.000,0.047]$. Binge eating and fat intake were positively related to binge drinking. Furthermore, emotional eating, external eating, and food addiction showed positive and statistically significant indirect relationships with binge drinking, whereas the relationship with restrained eating was negative. Conclusions: These findings point to the need to use a broader approach in understanding and preventing binge drinking in the youth population by showing the influence of the eating pattern on this problem. This information could be helpful in preventing future behaviors and improving interventions that address health risk behaviors.
\end{abstract}

Keywords: binge drinking; binge eating; fat intake; youth; undergraduate students

\section{Introduction}

The consumption of alcohol by young people has risen sharply in recent decades, and the risk of binge drinking in this population has increasingly been recognized [1]. In Spain, $25 \%$ of young people are considered binge drinkers [2]. Commonly, binge drinking is defined as the consumption of five or more drinks in men or four or more drinks in women on a single occasion (about $2 \mathrm{~h}$ ) [3]. This consumption pattern has become one of the main public health problems because it is associated with multiple adverse consequences, such as low quality of life, unsafe driving, aggressiveness, risky sexual behaviors, cognitive impairment, and emotional and relationship problems [4-7]. In addition, the high prevalence 
of binge drinking is especially worrisome in this developmental period, especially in young people, given that they are particularly vulnerable to the neurotoxic effects of alcohol, due to the functional and structural brain changes that occur at this stage [8]. Therefore, it is necessary to identify the risk factors associated with binge drinking in order to understand and prevent this behavior.

Currently, we have a large number of studies in the literature that point to a high comorbidity between eating disorders and alcohol consumption, including empirical studies [9], narrative reviews $[10,11]$, systematic reviews, and meta-analyses $[12,13]$. However, recently, the emphasis has begun to be placed not only on eating disorders as factors that can help to explain excessive alcohol consumption but also on intake and dietary patterns, such as fat intake and binge eating. In this sense, fat intake is understood as the frequency of consumption of "unhealthy fats", i.e., saturated fats and trans fats [14], and it has been associated with excessive alcohol consumption [15,16]. Along this line, studies in animal models show a greater preference for fats by rats previously injected with ethanol [15]. In addition, rats that consume more fat show a preference for consuming alcohol over water, a relationship that is not observed in rats that consume carbohydrates [17]. Moreover, evidence in humans also shows higher alcohol consumption by people with high fat consumption $[16,18,19]$. In this sense, it is hypothesized that this relationship can be explained by the activation of common pathways: fat intake activates the dopaminergic pathway, which is also involved in the processes of reward and motivation of alcohol consumption [20].

In addition, it has been shown that it is not only the type of diet (i.e., frequency of fat intake) but also the type of intake behavior (i.e., binge eating) that seems to contribute to explaining binge drinking [21]. Along this line, binge eating has been defined as the excessive intake of food (fat, carbohydrate, vegetables ... ) over a short-term period and the lack of control over this intake behavior [22,23]. According to different studies, binge eating and binge drinking share commonalities, regarding the pattern of behavior (impulsivity, loss of control), nature and onset of the problem, and prevalence, among others [24-28]. Given this, some authors explored whether binge eating is related to binge drinking and have concluded that both are associated [9,24,25,29-31]. This relation has also been seen in animal models [21].

Regarding binge eating and fat intake, it is well known that there are a variety of individual factors that can underlie high levels of binge eating and fat intake, such as sex, BMI, drive for thinness, body dissatisfaction, eating styles, among others [22,32-36]. Therefore, we aimed to study whether these factors can be indirectly related to binge drinking through their relationship with binge eating and/or fat intake. For example, it is known that people show different tendencies in their food behavior depending on their sex. In this case, literature has shown that there is a difference in prevalence between men and women. While women are more likely to binge [22], men are more likely to have a higher-fat diet in early adulthood [37]. On the other hand, individuals with a higher body mass index (BMI) report a greater number of binges [34] and a higher fat intake [38]. There is also a relationship between personality characteristics and these behaviors. In this sense, impulsivity may lie beneath binge eating and fat intake behaviors. Impulsivity can be defined as a predisposition toward rapid, unplanned reactions to internal or external stimuli without regard to the negative consequences of these reactions [39]. It can be understood that is composed of three components: motor impulsivity (acting without thinking), unplanned impulsivity (a lack of future orientation or forethought), and intentional impulsivity (inability to focus attention or concentrate) [40]. Literature showed that motor and intentional impulsivity seem to underlie both binge eating [41] and unhealthy food consumption [32]. Finally, eating styles may also be at the base of binge eating and fat intake behaviors. Van Strien et al. [42] distinguished three eating styles: emotional eating (eating in response to negative emotions), external eating (eating in response to external cues, such as sight or smell), and restrictive eating (deliberately restricting food to decrease or maintain weight). Studies indicate that both emotional and external eating are positively associated with increased fat intake [35,43], while restrictive eating is associated with decreased fat intake [44]. Furthermore, all three eating styles are associated with binge eating [34], and may act as strong predictors of binge eating [36,45]. 
Along the same line, the food addiction construct may act as a predictor of the severity of binge eating [33], and those who are addicted to food are also more likely than non-addicts to consume high-fat food [46]. Other variables that predispose to binge eating and fat intake are body dissatisfaction and drive for thinness, as they positively predict binge eating [47] and are negatively associated with fat intake [44,48].

So far, literature has indicated that binge drinking can predict an increase in binge eating and fat intake in young people [24,31]. However, a line of animal research has attempted to study the inverse relationship, suggesting that binge eating and fat intake may also play a role in the development of binge drinking [21]. These studies have explored the relationship, showing that both binge eating and fat intake predict an increase in subsequent ethanol overconsumption in adolescent mice [21]. However, the directionality of this relationship has hardly been studied, and the results are inconclusive [24]. The aforementioned evidence has raised the question of whether binge eating and fat intake might be influencing binge drinking [21], and to our knowledge, no research has focused on evaluating the relation among binge eating, fat intake, and binge drinking in this young population.

Therefore, the first aim of the present study was to explore the relationship between binge eating, fat intake, and binge drinking. Specifically, this model hypothesizes that binge eating and fat intake will positively influence binge drinking. Moreover, taking into account that there are individual factors that may be at the base of binge eating and fat intake, it is hypothesized that those factors can be indirectly related to binge drinking. In this sense, the second objective for this study was to analyze whether binge eating and fat intake mediate the relationship between these individual factors (sex, BMI, drive for thinness, body dissatisfaction, eating styles, impulsivity and food addiction) and binge drinking. With that in mind, we hypothesized that these individual factors may be acting on binge drinking through binge eating and fat intake. To accomplish these objectives, a structural equation model will be tested to study the relationships of binge drinking in the young population.

\section{Materials and Methods}

\subsection{Participants}

The sample of the present study was composed of undergraduate students living in the province of Valencia (Spain). A total of 428 undergraduate students, 324 females $(75.7 \%$; mean age 21.04; $\mathrm{SD}=4.22)$ and 104 males $(24.3 \%$; mean age 22.27 ; $\mathrm{SD}=5.39)$, took part voluntarily in the present study.

\subsection{Design and Procedure}

The study has a cross-sectional design, with data collection carried out at one time point. Data collection followed ethical requirements, and all participants were fully informed about the voluntary nature of their participation and the confidentiality of the collected data. They provided their informed consent prior to being included in the study. Participants were recruited through e-mail, social networks, and word of mouth, and they were directed to a dedicated online survey. The survey was carried out using the Lime Survey web platform, where participants provided demographic data and answered the questionnaires. The study was approved by the Valencia Ethics Committee and performed in accordance with the ethical standards of the 1964 Declaration of Helsinki (Procedure number: H1513854038939).

\subsection{Measures}

The structural model included several exogenous, mediation, and dependent variables. The exogenous variables were:

Sex, with two categories: men and women.

Body mass index (BMI). BMI was calculated by dividing self-reported current weight (in kilograms) by height squared (in meters) [49]. 
Eating disorders, measured with the Eating Disorder Inventory-3 (EDI-3; [50], in its Spanish version [51]). The EDI-3 is a self-report questionnaire consisting of 91 items grouped in 12 subscales designed to assess eating disorder psychopathology and the associated psychological symptoms. In the present study, only the eating disorder risk composite factor was used. The factor consists of 25 items rated on a 6-point Likert scale, and is composed of three scales that measure the risk of having an eating disorder: drive for thinness, bulimia, and body dissatisfaction. The bulimia scale is not used in the present study as it overlapped with the binge eating mediator variable. In this study, Cronbach's alpha was 0.903 for drive for thinness, and 0.747 for body dissatisfaction.

Eating styles, using the Dutch Eating Behavior Questionnaire (DEBQ; [42,52]). This questionnaire includes 33 items that measure emotional eating, external eating, and restrained eating. The questionnaire showed adequate levels of internal consistency, with a Cronbach's alpha value of 0.952 for emotional eating, 0.884 for external eating, and 0.926 for restrained eating.

Impulsivity. This variable was assessed using the Barratt Impulsiveness Scale-15 (BIS-15; [53]; Spanish version: [54]). It is a brief, self-administered scale composed of 15 items grouped in three factors: motor, non-planning, and attentional impulsivity. All the items evaluate impulsivity in different facets. Internal consistency estimates were 0.781 for motor impulsivity, 0.760 for non-planning impulsivity, and 0.690 for attentional impulsivity.

Food addiction, using the modified Yale Food Addiction Scale (mYFAS; [55]). The mYFAS evaluates signs of addictive-like eating behavior. It is composed of nine items consisting of one question from each of the symptom groups that make up the seven diagnostic criteria, plus two individual items that assess the presence of clinically significant impairment and distress. The internal consistency coefficient in this study, measured with Cronbach's alpha, was 0.769.

As regards the mediation variables, they included:

Binge eating. This variable was assessed using the total score on the Binge Eating Scale (BES; [56]; Spanish version: [57]). The BES is a 16-item self-report questionnaire designed to identify the symptoms associated with binge eating (eating large amounts of food in a short time and feeling loss of control). Internal consistency in this sample was 0.869 .

Fat intake. Fat intake consisted of the total score on the Short Fat Questionnaire (SFQ; [14]). This scale is a 17-item self-report questionnaire that assesses the weekly frequency of fat intake, such as fried food consumption, consumption of sauces or creams, use of fats for cooking, consumption of processed meat, cakes, ice cream, degree of cooking of food, and consumption of milk (with or without fat). For instance: "How many times a week do you eat French fries?" "And chocolate?", The response scale ranges from never to six times or more. Scores ranged from zero to 62, with a higher score indicating higher frequency of fat intake. This measure has been widely used in the young population to measure fat intake and it has been related to overweight, obesity, and substance use, among others [58,59].

This questionnaire had to undergo a rigorous cultural adaptation procedure. It was translated into English by a Spanish-English translator, and subsequently several Spanish reviewers adapted the translated items. The Spanish version of the SFQ is quite similar to the original validation [14]. Internal consistency in this sample, estimated with Cronbach's alpha, was 0.796.

Finally, the dependent variable in the model was binge drinking. This variable was measured with the main tools to assess binge drinking: item 3 from the AUDIT scale [60] ("How often do you have six or more drinks on one occasion?"), ranging from 0 (never) to 4 (daily or almost daily); and an indicator of binge drinking ("Considering all types of alcoholic beverages, did you ever have five or more drinks (four if you are female) in a two-hour period (one time) in the past month? How many times in the past month?"), ranging from 0 (never) to 4 (4 or more times per week) [61,62]. Internal consistency was 0.735 . 


\subsection{Statistical Analyses}

Analyses included descriptive statistics and a multiple indicators multiple causes (MIMIC) structural model. The MIMIC model allows us to study the relationships of binge drinking in a context free of measurement error in the main outcome under study, while considering unique relations with specific binge drinking indicators or items.

The model hypothesized, estimated, and tested a direct relationship between binge eating (measured with the Binge Eating Scale) and fat intake (measured with the Short Fat Questionnaire) and binge drinking, modeled as a latent factor. In addition, several variables related to binge eating and fat intake were included in the model to test its indirect effects (through binge eating and/or fat intake) on binge drinking. These variables were: sex, BMI, drive for thinness, body dissatisfaction, emotional eating, external eating, restrained eating, motor impulsivity, non-planning impulsivity, attentional impulsivity, and food addiction. The model can be consulted in Figure 1.

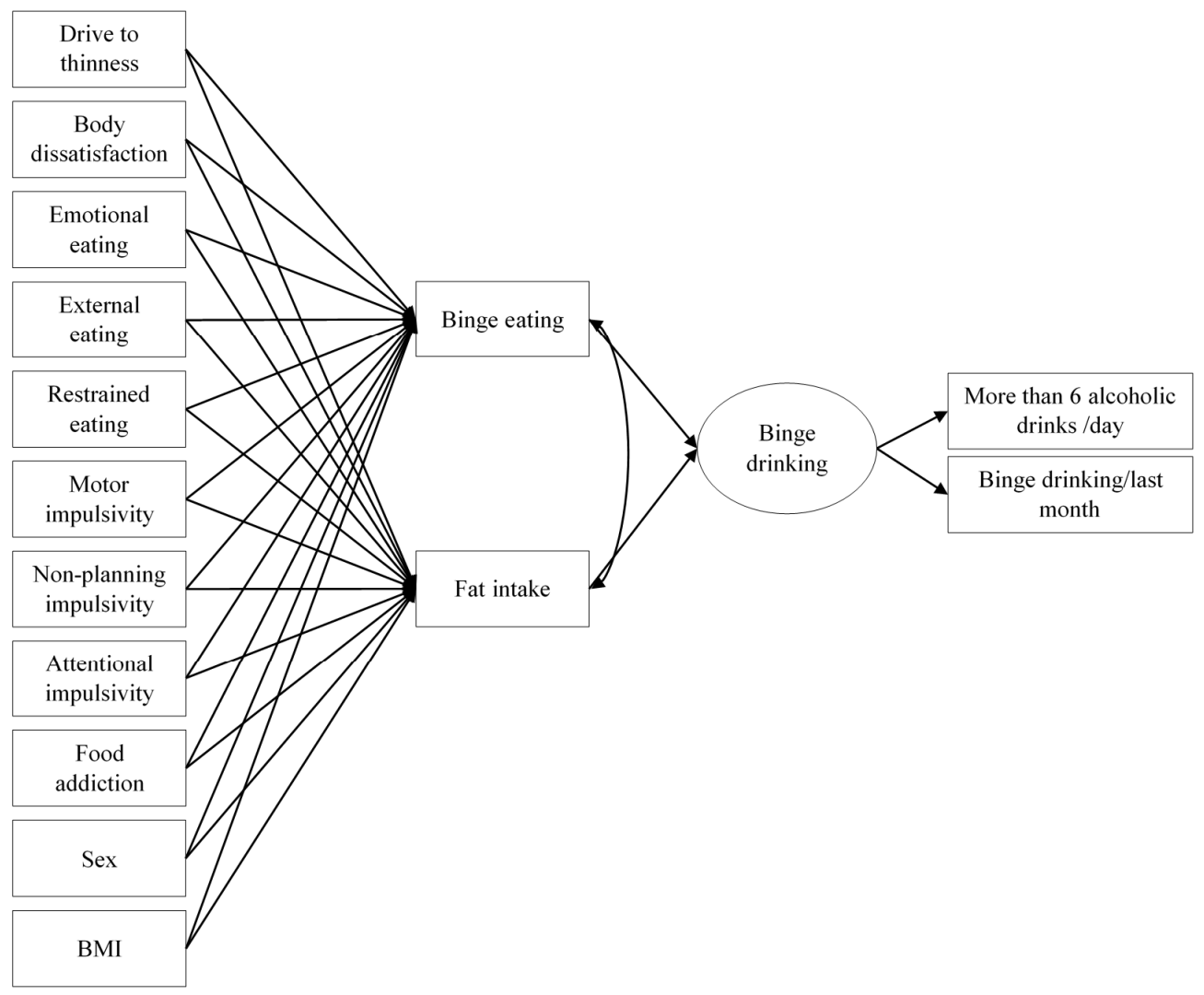

Figure 1. Multiple indicators multiple causes (MIMIC) model to study binge drinking; Notes: For the sake of clarity, standard errors are not shown.

The plausibility of the model was assessed using general fit criteria, in addition to examining the analytical fit. Regarding the general model fit, the fit statistics and indices recommended in the literature were used [63,64]: (a) Chi square statistic [65]; (b) comparative fit index (CFI), with values above 0.90 indicating a good representation of the data and, ideally, 0.95; [63]; and (c) root mean squared error of approximation (RMSEA), with values of 0.08 considered a reasonable fit [65], and its $90 \%$ confidence interval $(\mathrm{CI})$.

In the case of the analytical fit, factor loadings for the measurement part of the model were examined, along with the effects of the different variables involved. Indirect effects were also calculated, and the $\mathrm{CI}$ around the estimate of the effects was also estimated using a bootstrap resampling method. This procedure has been recommended as the best method to generate the required sampling distributions for testing indirect effects [66]. 
The model was estimated using maximum likelihood with robust standard errors (MLR), using Mplus version 8 [67].

\section{Results}

First, descriptive statistics were calculated for all the variables included in the model. As Table 1 shows, the scores on all the scales were in line with the average in the original validation, showing non-clinical symptomatology for binge eating, food addiction, and impulsivity. Specifically, in relation to the question "How often do you have 6 or more drinks in a single day?", only $0.7 \%$ of the participants reported having had six or more drinks in one day daily or almost daily; $4.0 \%$ did this weekly; $22.8 \%$, monthly; $37.8 \%$ less than once a month; and $34.6 \%$, never. Regarding the question "Considering all types of alcoholic beverages, did you have five or more drinks (four if you are female) in a two-hour period (one time) in the past month? How many times in the past month?", only $0.4 \%$ of the participants did this twice or three times a week; $9.8 \%$, two to four times a month; $27.4 \%$, once or less than once a month; and $62.4 \%$, never. These values were expected because the sample was drawn from the general population.

Table 1. Descriptive statistics for the variables under study.

\begin{tabular}{ccc}
\hline Variables & Mean & Standard Deviation \\
\hline BMI & 22.29 & 3.02 \\
Drive for thinness & 7.68 & 6.94 \\
Body dissatisfaction & 11.26 & 6.50 \\
Emotional eating & 25.99 & 10.70 \\
External eating & 30.27 & 7.33 \\
Restrained eating & 21.79 & 8.70 \\
Motor impulsivity & 4.66 & 4.11 \\
Non-planning impulsivity & 8.09 & 4.41 \\
Attentional impulsivity & 7.54 & 4.65 \\
Food addiction & 5.69 & 4.65 \\
Binge Eating Scale & 7.80 & 6.63 \\
Short Fat Questionnaire & 22.47 & 7.92 \\
More than 6 alcoholic drinks/day & 0.99 & 0.89 \\
Binge drinking/past month & 0.48 & 0.68 \\
\hline
\end{tabular}

Regarding the study of the relationships of binge drinking, a structural MIMIC model was hypothesized to relate the aforementioned variables to binge drinking. This initial or theoretical model (Figure 1) fitted the data perfectly: $\chi^{2}(23)=28.025(p=0.214)$, CFI $=0.992$, RMSEA $=0.023$ $[90 \% \mathrm{CI}=0.000,0.048]$. The measurement part of the model showed a strong link between the indicators and their corresponding latent variable (binge drinking), with a factor loading of $0.855(p<0.001)$ for more than 6 alcoholic drinks/day (item 3 on the AUDIT scale), and $0.663(p<0.001)$ for binge drinking episodes in the past month.

In terms of the relations with binge drinking, both binge eating and fat intake showed a positive and statistically significant relationship. Binge eating showed a positive effect of $0.226(p<0.001)$, and fat intake had a positive effect of $0.217(p<0.001)$. The correlation between these two indicators was, however, not statistically significant $(r=-0.021 ; p=0.684)$.

The exogenous variables that were related with binge eating were: drive for thinness $(\beta=0.284$, $p<0.001)$, body dissatisfaction $(\beta=0.108, p=0.019)$, emotional eating $(\beta=0.174, p<0.001)$, external eating $(\beta=0.119, p=0.004)$, restrained eating $(\beta=-0.122, p=0.026)$, and food addiction $(\beta=0.443$, $p<0.001)$. In the case of fat intake, the statistically significant related variables were: drive for thinness $(\beta=-0.184, p=0.018)$, external eating $(\beta=0.375, p<0.001)$, restrained eating $(\beta=-0.259, p<0.001)$, motor impulsivity $(\beta=0.132, p=0.013)$, and food addiction $(\beta=0.177, p=0.008)$. Correlations among the exogenous variables were in the expected direction and can be consulted in Table 2. 
Table 2. Correlations among the exogenous variables in the MIMIC model.

\begin{tabular}{|c|c|c|c|c|c|c|c|c|c|c|}
\hline Variables & 1 & 2 & 3 & 4 & 5 & 6 & 7 & 8 & 9 & 10 \\
\hline 1. Drive for thinness & - & & & & & & & & & \\
\hline 2. Body dissatisfaction & $0.608^{* * *}$ & - & & & & & & & & \\
\hline 3. Emotional eating & $0.377^{* * *}$ & $0.383 * * *$ & - & & & & & & & \\
\hline 4. External eating & $0.175^{* *}$ & $0.177^{* *}$ & $0.497^{* * *}$ & - & & & & & & \\
\hline 5. Restrained eating & $0.797^{* * *}$ & $0.504^{* * *}$ & $0.405^{* * *}$ & $0.226^{* * *}$ & - & & & & & \\
\hline 6. Motor impulsivity & $0.169 * *$ & $0.197^{* *}$ & 0.138 * & 0.163 ** & $0.190^{* *}$ & - & & & & \\
\hline 7. Non-planning impulsivity & 0.001 n.s. & 0.071 n.s. & 0.104 n.s. & 0.103 n.s. & 0.020 n.s. & $0.327^{* * *}$ & - & & & \\
\hline 8. Attentional impulsivity & $0.132 *$ & $0.264^{* * *}$ & $0.230 * * *$ & $0.214^{* * *}$ & 0.101 n.s. & $0.284^{* * *}$ & $0.266^{* * *}$ & - & & \\
\hline 9. Food addiction & $0.558^{* * *}$ & $0.512 * * *$ & $0.613^{* * *}$ & $0.403^{* * *}$ & $0.561^{* * *}$ & $0.299 * * *$ & 0.092 n.s. & $0.225^{* * *}$ & - & \\
\hline 10. Sex & $0.247^{* * *}$ & $0.147^{* *}$ & $0.210^{* * *}$ & $0.143 * *$ & $0.213^{* * *}$ & -0.093 n.s. & $-0.117^{*}$ & $-0.107 *$ & 0.062 n.s. & - \\
\hline 11. BMI & $0.260^{* * *}$ & $0.317^{* * *}$ & $0.159 * *$ & -0.018 n.s. & $0.242^{* * *}$ & 0.062 n.s. & 0.086 n.s. & 0.105 * & $0.184^{* *}$ & $-0.220^{* * *}$ \\
\hline
\end{tabular}

Notes: Sex was coded as: $0=$ men, 1 = women; positive correlations indicate higher levels for women, whereas negative correlations indicate higher levels for men; n.s. $p>0.050$; $p<0.050$; ${ }^{* *} p<0.010$; ${ }^{* * *} p<0.001$. 
Finally, indirect effects of the exogenous variables on the binge drinking factor were examined. As shown in Table 3, emotional eating, external eating, and food addiction showed positive, statistically significant relations with binge drinking, whereas the relationship with restrained eating was negative.

Table 3. Indirect effects of the exogenous variables on the binge drinking factor in the MIMIC model.

\begin{tabular}{cccc}
\hline Variables & $\begin{array}{c}\text { Effect through Binge } \\
\text { Eating }[\mathbf{9 5 \%} \text { CI] }\end{array}$ & $\begin{array}{c}\text { Effect through Fat } \\
\text { Intake }[95 \% \text { CI] }\end{array}$ & Total Effect [95\% CI] \\
\hline Drive for thinness & $0.064^{* *}[0.029,0.120]$ & $-0.040^{*}[-0.096,-0.008]$ & 0.024 n.s. $[-0.031,0.085]$ \\
Body dissatisfaction & $0.024^{*}[0.005,0.054]$ & 0.006 n.s. $[-0.019,0.036]$ & 0.031 n.s. $[-0.004,0.076]$ \\
Emotional eating & $0.039^{* *}[0.016,0.076]$ & 0.002 n.s. $[-0.025,0.032]$ & $0.042^{*}[0.006,0.089]$ \\
External eating & $0.027^{*}[0.009,0.057]$ & $0.081^{* *}[0.035,0.143]$ & $0.108^{* * *}[0.055,0.175]$ \\
Restrained eating & -0.028 n.s. $[-0.064,0.005]$ & $-0.056^{* *}[-0.117,-0.020]$ & $-0.084^{* *}[-0.151,-0.038]$ \\
Motor impulsivity & -0.011 n.s. $[-0.037,0.007]$ & $0.029^{*}[0.006,0.068]$ & 0.017 n.s. $[-0.013,-0.057]$ \\
Non-planning impulsivity & 0.019 n.s. $[-0.003,0.042]$ & -0.017 n.s. $[-0.047,0.001]$ & 0.002 n.s. [-0.028, 0.029] \\
Attentional impulsivity & 0.004 n.s. $[-0.011,0.023]$ & -0.006 n.s. $[-0.034,0.015]$ & -0.002 n.s. $[-0.033,0.026]$ \\
Food addiction & $0.100^{* * *}[0.045,0.166]$ & $0.038^{*}[0.010,0.087]$ & $0.139 * *[0.072,0.218]$ \\
Sex & 0.005 n.s. $[-0.008,0.023]$ & -0.004 n.s. $[-0.029,0.017]$ & 0.002 n.s. $[-0.026,0.027]$ \\
BMI & 0.013 n.s. $[0.000,0.032]$ & -0.011 n.s. $[-0.036,0.007]$ & 0.002 n.s. $[-0.024,0.028]$ \\
\hline
\end{tabular}

Notes: Sex was coded as: $0=$ men, $1=$ women; positive correlations indicate higher levels for women, whereas negative correlations indicate higher levels for men; n.s. $p>0.050 ;{ }^{*} p<0.050 ;{ }^{* *} p<0.010$; ${ }^{* *} p<0.001$.

Overall, $68.3 \%$ of binge eating $\left(R^{2}=0.683, p<0.001\right), 27.0 \%$ of fat intake $\left(R^{2}=0.270, p<0.001\right)$, and $10.4 \%$ of binge drinking $\left(R^{2}=0.104, p=0.015\right)$ were explained.

\section{Discussion}

Firstly, the current study examined whether binge eating and fat intake are related to binge drinking in a youth sample. As it was hypothesized, binge eating and fat intake are related to binge drinking, meaning that higher scores on binge eating and higher fat intake behaviors are associated with higher scores on binge drinking behaviors. These findings are in line with recent studies in animal models that showed a causal relationship between a high-fat diet and binge eating behaviors with higher consumption of ethanol [21]. Along the same line, other authors have also proposed a relationship between fat intake and binge drinking [15-19], and between binge eating and binge drinking $[24,25]$. Furthermore, prospective studies have found that binge eating predicts the risk of frequent drinking and substance abuse $[68,69]$ or drug consumption [13,70]. It has been hypothesized that binge eating induces emotions of guilt and shame, and alcohol and substance use could be used to regulate these negative emotions [71].

In addition, there are other mechanisms that may be at the base of binge eating and fat intake, such as eating styles $[34,44,45]$ or food addiction $[33,46]$, among others, that could help explain these relationships.

Taking this into account, secondly, the mediating role of binge eating and fat intake between various individual factors (sex, BMI, drive for thinness, body dissatisfaction, eating styles, impulsivity and food addiction) and binge drinking was examined. Therefore, it was hypothesized that these individual factors may be acting on binge drinking through binge eating and fat intake. As hypothesized, binge drinking is indirectly related to other relevant variables. Specifically, emotional eating, external eating, and food addiction showed positive and statistically significant indirect relationships with binge drinking, whereas the relationship with restrained eating was negative.

First, our results showed that emotional eating was positively related to binge drinking through its relationship with binge eating. These findings replicate some results obtained in previous research. There is evidence that emotional eating can act as a predictor of binge eating [34,36], but it was not yet known whether binge eating could also act as a mediator between emotional eating and binge drinking. In these results, we can conclude that people who eat more in response to negative emotions may be more likely to have higher binge eating scores, and in turn, engaging in binge eating may contribute to higher alcohol consumption. 
Second, our results showed that external eating was positively related to drinking behaviors through its relationship with binge eating and fat intake. There is evidence in the literature about the positive relationship between external eating and binge eating [34,45], and between external eating and fat intake [35,43], but our study is the first to analyze the mediating role of binge eating and fat intake in the relationship between external eating and binge drinking.

Third, our results showed that restrained eating was associated with lower binge drinking behaviors, and this relationship was mediated by the decrease in fat intake. Although the literature has found that restrained eating often leads to higher alcohol consumption, our data could suggest the role of fat intake in better understanding this relationship. That is, people who restrict food and eat less fat will drink less alcohol, possibly because of the calories in both substances. Moreover, a recent study pointed out that alcohol consumption and restrictive behaviors are weakly related [72], and a potential explanatory hypothesis would be that fat intake acts as a mediator between these variables.

Fourth, food addiction was related to binge eating and fat intake, and through these behaviors, it could lead to an increase in alcohol consumption in the form of binge drinking. Although the literature has pointed out the relationship between food addiction and alcohol [73,74], our study suggests that binge eating and fat intake could act as mediating factors in this relationship.

Several limitations must be highlighted in the present study. The sample was limited to undergraduate students. Therefore, these findings cannot be generalized to other demographic groups such as young people with a low-medium educational status or adults, in whom the prevalence of binge drinking has also been found to be very high. Thus, further studies are required. In the present study, binge drinking was measured with two indicators commonly used in the literature: frequency of consumption of high alcohol doses from the AUDIT-3, and the presence of a binge drinking episode in the past. Both indicators showed an adequate factorial saturation indicating that they worked well as measures of binge drinking, and this result is consistent with the literature [60,62]. Although this is the most common measure used, the research still does not have a standardized measure for binge drinking, and future studies are needed in this field to create a comprehensive and standardized measure. Moreover, other future lines may include testing the model invariance in different subgroups, such as women and men, to detect possible different paths for different populations. Another limitation is the cross-sectional nature of the study, which calls for a cautious interpretation of the results, with other alternative models being possible [75]. Therefore, future research is needed to examine the interactions among these variables in a longitudinal design that makes it possible to assess the temporal relationships between them. In addition, the study was carried out with self-report measures, which may be subject to self-report bias and yield different results compared to clinical interviews or semi-structured assessments [76]. Furthermore, it should also be noted that the explained variance of binge drinking in the present model is small. For future research, it would be necessary to include other relevant factors traditionally related to binge drinking, as well as a sample with a wider variety of characteristics (such as age or the presence of risk factors related to health), to improve the explanatory capability of the current model. Finally, it should be noted the importance for future studies to explore the role of other nutrients, such as carbohydrates, since they can also play an important role in alcohol consumption. In the present study, only the role of high-fat foods has been studied, given its current prevalence of consumption, its negative health consequences, as well as its relationship with alcohol consumption in rodents. This is the first study to explore the relationship between fat intake and binge drinking in young adults, but future research should explore how different nutrients (fats and carbohydrates) separately influence binge drinking.

\section{Conclusions}

This study provides evidence of a direct relationship between binge eating and fat intake and binge drinking, and an indirect relationship between different eating patterns (emotional, restrictive and external eating, and food addiction) and binge drinking, mediated through binge eating and fat 
intake. The present study is the first to transfer the previous results in mice to humans and assess the influence of eating patterns on binge drinking.

The results of this study can have several implications for health professionals and researchers interested in promoting health and preventing risk behaviors in young people, such as binge drinking, by helping to improve interventions that aim to prevent or decrease binge drinking in young populations. Prevention and intervention strategies could target young people with high scores on these eating patterns to weaken the association between these eating patterns and binge drinking. More specifically, it should be noted that binge eating and fat intake could be a gateway to the initiation and escalation of binge drinking. If we focus on improving these eating patterns in young populations, this can have a dampening effect on the level of alcohol consumption among young people and its consequences. In addition, it should be considered that eating styles (emotional, external, and restrained eating) and food addiction may also precipitate binge drinking through the relationship with binge eating and fat intake. Taking into account this study, it would be appropriate to focus on those young people who have high scores in those eating styles, and who show high scores in food addiction, in order to try to improve those eating patterns as much as possible and thus reduce the binge drinking pattern.

Despite some limitations, these findings provide a unique contribution to the current understanding of the relationship between eating patterns and binge drinking in young people. All these eating patterns are variables to be considered for future interventions and prevention of binge drinking among young people, given their association with binge drinking; however, further research is needed to determine whether these eating patterns can actually explain the high prevalence of binge drinking.

Author Contributions: Conceptualization, T.E.-M., M.R.-A. and R.M.B.; methodology, T.E.-M. and L.G.; software, T.E.-M., L.G. and R.H.; formal analysis, T.E.-M., L.G. and R.H.; resources, M.R.-A. and R.M.B.; data curation, T.E.-M., L.G. and R.H.; writing-original draft preparation, T.E.-M., L.G. and R.H.; writing-review and editing, all authors; supervision, M.R.-A. and R.M.B.; funding acquisition, M.R.-A. and R.M.B. All authors have read and agreed to the published version of the manuscript.

Funding: This study was supported by the Spanish Ministry of Health, Social Affairs and Equality, Government Delegation for the National Drug Plan (PNSD 2018I013), PROMETEO program (Generalitat Valenciana. Conselleria de Educación, Dirección General de Política Científica PROMETEO 2018/132), and Excellence Research Program PROMETEO (“INTERSABIAS" project-PROMETEO/2018/110/Conselleria d'Educació, Investigació, Cultura I Esport, Generalitat Valenciana).

Acknowledgments: T.E.-M. is grateful to the Ministerio de Universidades for the FPU doctoral scholarship (FPU16/01875). This work was supported by CIBEROBN, an initiative of the ISCIII (ISC III CB06 03/0052).

Conflicts of Interest: The authors declare no conflict of interest.

\section{Abbreviations}

$\begin{array}{ll}\text { CFI } & \text { Comparative Fit Index } \\ \text { CI } & \text { Confidence Interval } \\ \text { MIMIC } & \text { Multiple Indicators Multiple Causes } \\ \text { MLR } & \text { Maximum Likelihood with Robust standard errors } \\ \text { RMSEA } & \text { Root Mean Squared Error of Approximation }\end{array}$

\section{References}

1. World Health Organization. Global Status Report on Alcohol and Health; World Health Organization: Geneva, Switzerland, 2014; Available online: http://www.who.int/substance_abuse/publications/global_alcohol_ report/en/ (accessed on 10 October 2020).

2. Ministerio de Sanidad, Consumo y Bienestar Social, Plan Nacional sobre Drogas. Encuesta EDADES 2017: Encuesta Sobre Alcohol y otras drogas en España (EDADES), 1995-2017. Available online: http://www.pnsd.mscbs. gob.es/profesionales/sistemasInformacion/sistemaInformacion/pdf/EDADES_2017_Informe.pdf (accessed on 15 May 2020).

3. National Institute of Alcohol Abuse and Alcoholism. NIAAA Council Approves Definition of Binge Drinking. Available online: https://cutt.ly/EwQHD2G (accessed on 26 November 2020). 
4. Cservenka, A.; Brumback, T. The burden of binge and heavy drinking on the brain: Effects on adolescent and young adult neural structure and function. Front Psychol. 2017, 8, 1111. [CrossRef] [PubMed]

5. Kuntsche, E.; Kuntsche, S.; Thrul, J.; Gmel, G. Binge drinking: Health impact, prevalence, correlates and interventions. Psychol. Health 2017, 32, 976-1017. [CrossRef] [PubMed]

6. Martinotti, G.; Lupi, M.; Carlucci, L.; Santacroce, R.; Cinosi, E.; Acciavatti, T.; Sarchione, F.; Verrastro, V.; Diotaiuti, P.; Petruccelli, I.; et al. Alcohol drinking patterns in young people: A survey-based study. J. Health Psychol. 2017, 22, 1889-1896. [CrossRef] [PubMed]

7. Patrick, M.E.; Terry-McElrath, Y.M.; Evans-Polce, R.J.; Schulenberg, J.E. Negative alcohol-related consequences experienced by young adults in the past 12 months: Differences by college attendance, living situation, binge drinking, and sex. Addict. Behav. 2020, 105, 106320. [CrossRef]

8. Jones, S.A.; Lueras, J.M.; Nagel, B.J. Effects of binge drinking on the developing brain: Studies in humans. Alcohol Res. Curr. Rev. 2018, 39, 87-96.

9. Bahji, A.; Mazhar, M.N.; Hudson, C.C.; Nadkarni, P.; MacNeil, B.A.; Hawken, E. Prevalence of substance use disorder comorbidity among individuals with eating disorders: A systematic review and meta-analysis. Psychiatry Res. 2019, 273, 58-66. [CrossRef]

10. Conason, A.H.; Sher, L. Alcohol use in adolescents with eating disorders. Int. J. Adolesc. Med. Health 2006, 18, 31-36. [CrossRef]

11. Gadalla, T.; Piran, N. Co-occurrence of eating disorders and alcohol use disorders in women: A meta-analysis. Arch. Women Ment. Health 2007, 10, 133-140. [CrossRef]

12. Schulte, E.M.; Grilo, C.M.; Gearhardt, A.N. Shared and unique mechanisms underlying binge eating disorder and addictive disorders. Clin. Psychol. Rev. 2016, 44, 125-139. [CrossRef]

13. Sonneville, K.R.; Horton, N.J.; Micali, N.; Crosby, R.D.; Swanson, S.A.; Solmi, F.; Field, A.E. Longitudinal associations between binge eating and overeating and adverse outcomes among adolescents and young adults: Does loss of control matter? JAMA Pediatr. 2013, 167, 149-155. [CrossRef]

14. Dobson, A.J.; Blijlevens, R.; Alexander, H.M.; Croce, N.; Heller, R.F.; Higginbotham, N.; Pike, G.; Plotnikoff, R.; Russell, A.; Walker, R. Short fat questionnaire: A self-administered measure of fat-intake behaviour. Aust. J. Public Health 1993, 17, 144-149. [CrossRef]

15. Barson, J.R.; Karatayev, O.; Chang, G.Q.; Johnson, D.F.; Bocarsly, M.E.; Hoebel, B.G.; Leibowitz, S.F. Positive relationship between dietary fat, ethanol intake, triglycerides, and hypothalamic peptides: Counteraction by lipid-lowering drugs. Alcohol 2009, 43, 433-441. [CrossRef]

16. Stickley, A.; Koyanagi, A.; Koposov, R.; McKee, M.; Murphy, A.; Ruchkin, V. Binge drinking and eating problems in Russian adolescents. Alcohol. Clin. Exp. Res. 2015, 39, 540-547. [CrossRef]

17. Krahn, D.D.; Gosnell, B.A. Fat-preferring rats consume more alcohol than carbohydrate-preferring rats. Alcohol 1991, 8, 313-316. [CrossRef]

18. Swinburn, B.A.; Walter, L.; Ricketts, H.; Whitlock, G.; Law, B.; Norton, R.; Jackson, R.; MacMahon, S. The determinants of fat intake in a multi-ethnic New Zealand population. Int. J. Epidemiol. 1998, 27, 416-421. [CrossRef] [PubMed]

19. Kesse, E.; Clavel-Chapelon, F.; Slimani, N.; Van Liere, M. Do eating habits differ according to alcohol consumption? Results of a study of the French cohort of the European Prospective Investigation into Cancer and Nutrition (E3N-EPIC). Am. J. Clin. Nutr. 2001, 74, 322-327. [CrossRef] [PubMed]

20. Valdivia, S.; Cornejo, M.P.; Reynaldo, M.; De Francesco, P.N.; Perello, M. Escalation in high fat intake in a binge eating model differentially engages dopamine neurons of the ventral tegmental area and requires ghrelin signaling. Psychoneuroendocrinology 2015, 60, 206-216. [CrossRef] [PubMed]

21. Blanco-Gandía, M.C.; Ledesma, J.C.; Aracil-Fernández, A.; Navarrete, F.; Montagud-Romero, S.; Aguilar, M.A.; Manzanares, J.; Miñarro, J.; Rodríguez-Arias, M. The rewarding effects of ethanol are modulated by binge eating of a high-fat diet during adolescence. Neuropharmacology 2017, 121, 219-230. [CrossRef]

22. American Psychiatric Association. Diagnostic and Statistical Manual of Mental Disorders (DSM-5), 5th ed.; American Psychiatric Association: Arlington, VA, USA, 2013.

23. Fitzgibbon, M.L.; Blackman, L.R. Binge eating disorder and bulimia nervosa: Differences in the quality and quantity of binge eating episodes. Int. J. Eat. Disord. 2000, 27, 238-243. [CrossRef]

24. Escrivá-Martínez, T.; Herrero, R.; Molinari, G.; Rodríguez-Arias, M.; Verdejo-García, A.; Baños, R.M. Binge Eating and Binge Drinking: A Two-Way Road? An Integrative Review. Curr. Pharm. Des. 2020, 26, 2402-2415. [CrossRef] 
25. Ferriter, C.; Ray, L.A. Binge eating and binge drinking: An integrative review. Eat Behav. 2011, 12, 99-107. [CrossRef] [PubMed]

26. Patrick, M.E.; Terry-McElrath, Y.M.; Lanza, S.T.; Jager, J.; Schulenberg, J.E.; O'Malley, P.M. Shifting age of peak binge drinking prevalence: Historical changes in normative trajectories among young adults aged 18 to 30. Alcohol. Clin. Exp. Res. 2019, 43, 287-298. [CrossRef] [PubMed]

27. Stice, E.; Marti, C.N.; Rohde, P. Prevalence, incidence, impairment, and course of the proposed DSM-5 eating disorder diagnoses in an 8-year prospective community study of young women. J. Abnorm. Psychol. 2013, 122, 445-457. [CrossRef]

28. Croll, J.K.; Neumark-Sztainer, D.; Story, M.; Ireland, M. Prevalence and risk and protective factors related to disordered eating behaviors among adolescents: Relationship to gender and ethnicity. J. Adolesc. Health 2002, 31, 166-175. [CrossRef]

29. Davis, C.; Mackew, L.; Levitan, R.D.; Kaplan, A.S.; Carter, J.C.; Kennedy, J.L. Binge Eating Disorder (BED) in Relation to addictive behaviors and personality risk factors. Front. Psychol. 2017, 8, 579. [CrossRef] [PubMed]

30. Laghi, F.; Baiocco, R.; Liga, F.; Lonigro, A.; Baumgartner, E. Binge eating and binge drinking behaviors: Individual differences in adolescents' identity styles. J. Health Psychol. 2014, 19, 333-343. [CrossRef] [PubMed]

31. Vogeltanz-Holm, N.D.; Wonderlich, S.A.; Lewis, B.A.; Wilsnack, S.C.; Harris, T.R.; Wilsnack, R.W.; Kristjanson, A.F. Longitudinal predictors of binge eating, intense dieting, and weight concerns in a national sample of women. Behav. Ther. 2000, 31, 221-235. [CrossRef]

32. Kakoschke, N.; Kemps, E.; Tiggemann, M. External eating mediates the relationship between impulsivity and unhealthy food intake. Physiol. Behav. 2015, 147, 117-121. [CrossRef]

33. Linardon, J.; Messer, M. Assessment of food addiction using the Yale Food Addiction Scale 2.0 in individuals with binge-eating disorder symptomatology: Factor structure, psychometric properties, and clinical significance. Psychiatry Res. 2019, 279, 216-221. [CrossRef]

34. Mason, T.B.; Lewis, R.J. Profiles of binge eating: The interaction of depressive symptoms, eating styles, and body mass index. Eat. Disord. 2014, 22, 450-460. [CrossRef]

35. Camilleri, G.M.; Méjean, C.; Kesse-Guyot, E.; Andreeva, V.A.; Bellisle, F.; Hercberg, S.; Péneau, S. The associations between emotional eating and consumption of energy-dense snack foods are modified by sex and depressive symptomatology. J. Nutr. 2014, 144, 1264-1273. [CrossRef]

36. Sultson, H.; Kukk, K.; Akkermann, K. Positive and negative emotional eating have different associations with overeating and binge eating: Construction and validation of the Positive-Negative Emotional Eating Scale. Appetite 2017, 116, 423-430. [CrossRef] [PubMed]

37. Li, K.K.; Concepcion, R.Y.; Lee, H.; Cardinal, B.J.; Ebbeck, V.; Woekel, E.; Readdy, R.T. An examination of sex differences in relation to the eating habits and nutrient intakes of university students. J. Nutr. Educ. Behav. 2012, 44, 246-250. [CrossRef] [PubMed]

38. Wang, L.; Wang, H.; Zhang, B.; Popkin, B.M.; Du, S. Elevated Fat Intake Increases Body Weight and the Risk of Overweight and Obesity among Chinese Adults: 1991-2015 Trends. Nutrients 2020, 12, 3272. [CrossRef] [PubMed]

39. Moeller, F.G.; Barratt, E.S.; Dougherty, D.M.; Schmitz, J.M.; Swann, A.C. Psychiatric aspects of impulsivity. Am. J. Psychiatry. 2001, 158, 1783-1793. [CrossRef] [PubMed]

40. Barratt, E.S. Impulsiveness subtraits: Arousal and information processing. In Motivation, Emotion and Personality; Spence, J.T., Izard, C.E., Eds.; Elsevier Science Publishers: Amsterdam, The Netherlands, 1985; pp. 137-146.

41. Meule, A. Impulsivity and overeating: A closer look at the subscales of the Barratt Impulsiveness Scale. Front. Psychol. 2013, 4, 177. [CrossRef]

42. Van Strien, T.; Frijters, J.E.; Bergers, G.P.; Defares, P.B. The Dutch Eating Behavior Questionnaire (DEBQ) for assessment of restrained, emotional, and external eating behavior. Int. J. Eat. Disord. 1986, 5, 295-315. [CrossRef]

43. Anschutz, D.J.; Van Strien, T.; Van De Ven, M.O.; Engels, R.C. Eating styles and energy intake in young women. Appetite 2009, 53, 119-122. [CrossRef]

44. Liebman, M.; Cameron, B.A.; Carson, D.K.; Brown, D.M.; Meyer, S.S. Dietary fat reduction behaviors in college students: Relationship to dieting status, gender and key psychosocial variables. Appetite 2001, 36, 51-56. [CrossRef] 
45. Burton, P.; Smit, H.J.; Lightowler, H.J. The influence of restrained and external eating patterns on overeating. Appetite 2007, 49, 191-197. [CrossRef]

46. Ruddock, H.K.; Field, M.; Hardman, C.A. Exploring food reward and calorie intake in self-perceived food addicts. Appetite 2017, 115, 36-44. [CrossRef]

47. Gordon, K.H.; Holm-Denoma, J.M.; Troop-Gordon, W.; Sand, E. Rumination and body dissatisfaction interact to predict concurrent binge eating. Body Image 2012, 9, 352-357. [CrossRef] [PubMed]

48. Ribeiro-Silva, R.D.C.; Fiaccone, R.L.; Conceição-Machado, M.E.P.D.; Ruiz, A.S.; Barreto, M.L.; Santana, M.L.P. Body image dissatisfaction and dietary patterns according to nutritional status in adolescents. J. Pediatr. 2018, 94, 155-161. [CrossRef] [PubMed]

49. World Health Organization. Obesity: Preventing and Managing the Global Epidemic; World Health Organization: Geneva, Switzerland, 2000; Available online: http://www.worldcat.org/title/obesity-preventing-andmanaging-the-global-epidemic-report-of-a-who-consultation/oclc/48171257 (accessed on 10 October 2020).

50. Clausen, L.; Rosenvinge, J.H.; Friborg, O.; Rokkedal, K. Validating the Eating Disorder Inventory-3 (EDI-3): A Comparison between 561 Female Eating Disorders Patients and 878 Females from the General Population. J. Psychopathol. Behav. Assess. 2011, 33, 101-110. [CrossRef]

51. Elosua, P.; López-Jáuregui, A. Internal Structure of the Spanish Adaptation of the Eating Disorder Inventory-3. Eur. J. Psychol. Assess. 2012, 28, 25-31. [CrossRef]

52. Cebolla, A.; Barrada, J.R.; Van Strien, T.; Oliver, E.; Baños, R. Validation of the Dutch Eating Behavior Questionnaire (DEBQ) in a sample of Spanish women. Appetite 2014, 73, 58-64. [CrossRef]

53. Spinella, M. Normative data and a short form of the Barrat Impulsiveness Scale. Int. J. Neurosci. 2007, 117, 359-368. [CrossRef] [PubMed]

54. Orozco-Cabal, L.; Rodríguez, M.; Herin, D.V.; Gempeler, J.; Uribe, M. Validity and Reliability of the Abbreviated Barratt Impulsiveness Scale in Spanish (BIS-15S)*. Rev. Colomb. Psiquiatr. 2010, 39, 93-109. [CrossRef]

55. Flint, A.J.; Gearhardt, A.N.; Corbin, W.R.; Brownell, K.D.; Field, A.E.; Rimm, E.B. Food-addiction scale measurement in 2 cohorts of middle-aged and older women. Am. J. Clin. Nutr. 2014, 99, 578-586. [CrossRef]

56. Gormally, J.; Black, S.; Daston, S.; Rardin, D. The assessment of binge eating severity among obese persons. Addict. Behav. 1982, 7, 47-55. [CrossRef]

57. Escrivá-Martínez, T.; Galiana, L.; Rodriguez-Arias, M.; Baños, R.M. The binge eating scale: Structural equation competitive models, invariance measurement between sexes, and relationships with food addiction, impulsivity, binge drinking, and body mass index. Front. Psychol. 2019, 10, 530. [CrossRef] [PubMed]

58. Hayatbakhsh, M.R.; O'Callaghan, M.J.; Mamun, A.A.; Williams, G.M.; Clavarino, A.; Najman, J.M. Cannabis use and obesity and young adults. Am. J. Drug Alcohol Abus. 2010, 36, 350-356. [CrossRef] [PubMed]

59. O'Connor, J.; Steinbeck, K.; Hill, A.; Booth, M.; Kohn, M.; Shah, S.; Baur, L. Evaluation of a community-based weight management program for overweight and obese adolescents: The Loozit study. Nutr. Diet. 2008, 65, 121-127. [CrossRef]

60. Maurage, P.; Lannoy, S.; Mange, J.; Grynberg, D.; Beaunieux, H.; Banovic, I.; Gierski, F.; Naassila, M. What we talk about when we talk about binge drinking: Towards an integrated conceptualization and evaluation. Alcohol Alcohol. 2020, 55, 468-479. [CrossRef] [PubMed]

61. Kuntsche, E.; Gmel, G.; Wicki, M.; Rehm, J.; Grichting, E. Disentangling gender and age effects on risky single occasion drinking during adolescence. Eur. J. Public Health 2006, 16, 670-675. [CrossRef]

62. Paul, L.A.; Grubaugh, A.L.; Frueh, B.C.; Ellis, C.; Egede, L.E. Associations between binge and heavy drinking and health behaviors in a nationally representative sample. Addict. Behav. 2011, 36, 1240-1245. [CrossRef]

63. Hu, L.; Bentler, P.M. Cut-off criteria for fit indexes in covariance structure analysis: Conventional criteria versus new alternatives. Struct. Equ. Modeling 1999, 6, 1-55. [CrossRef]

64. Tanaka, J.S. Multifaceted conceptions of fit in structural equation models. In Testing Structural Equation Models; Bollen, K.A., Long, J.S., Eds.; Sage: Newbury Park, CA, USA, 1993; pp. 10-39.

65. Kline, R.B. Principles and Practices of Structural Equation Modeling, 3rd ed.; Guilford Press: New York, NY, USA, 2015.

66. MacKinnon, D.P.; Fairchild, A.J.; Fritz, M.S. Mediation analysis. Annu. Rev. Psychol. 2007, 58, 593-614. [CrossRef]

67. Muthén, L.K.; Muthén, B.O. Confirmatory factor analysis and structural equation modeling. In Mplus User's Guide, 8th ed.; Muthén \& Muthén: Los Angeles, CA, USA, 2017; pp. 55-112. 
68. Field, A.E.; Sonneville, K.R.; Micali, N.; Crosby, R.D.; Swanson, S.A.; Laird, N.M.; Treasure, J.; Solmi, F.; Horton, N.J. Prospective association of common eating disorders and adverse outcomes. Pediatrics 2012, 130, e289-e295. [CrossRef]

69. Measelle, J.R.; Stice, E.; Hogansen, J.M. Developmental trajectories of co-occurring depressive, eating, antisocial, and substance abuse problems in female adolescents. J. Abnorm. Psychol. 2006, 115, 524-538. [CrossRef]

70. Micali, N.; Solmi, F.; Horton, N.J.; Crosby, R.D.; Eddy, K.T.; Calzo, J.P.; Sonneville, K.R.; Swanson, S.A.; Field, A.E. Adolescent Eating Disorders Predict Psychiatric, High-Risk Behaviors and Weight Outcomes in Young Adulthood. J. Am. Acad. Child. Adolesc. Psychiatry 2015, 54, 652-659. [CrossRef] [PubMed]

71. Caton, S.J.; Nolan, L.J.; Hetherington, M.M. Alcohol, Appetite and Loss of Restraint. Curr. Obes. Rep. 2015, 4, 99-105. [CrossRef] [PubMed]

72. Baker, J.H.; Munn-Chernoff, M.A.; Lichtenstein, P.; Larsson, H.; Maes, H.; Kendler, K.S. Shared familial risk between bulimic symptoms and alcohol involvement during adolescence. J. Abnorm. Psychol. 2017, 126, 506-518. [CrossRef] [PubMed]

73. Gearhardt, A.N.; Corbin, W.R.; Brownell, K.D. Preliminary validation of the Yale food addiction scale. Appetite 2009, 52, 430-436. [CrossRef]

74. Gearhardt, A.N.; Corbin, W.R.; Brownell, K.D. Food addiction: An examination of the diagnostic criteria for dependence. J. Addict. Med. 2009, 3, 1-7. [CrossRef]

75. MacCallum, R.C.; Austin, J.T. Applications of structural equation modeling in psychological research. Annu. Rev. Psychol. 2000, 51, 201-226. [CrossRef]

76. Berg, K.C.; Peterson, C.B.; Frazier, P.; Crow, S.J. Psychometric evaluation of the eating disorder examination and eating disorder examination-questionnaire: A systematic review of the literature. Int. J. Eat. Disord. 2012, 45, 428-438. [CrossRef]

Publisher's Note: MDPI stays neutral with regard to jurisdictional claims in published maps and institutional affiliations.

(C) 2020 by the authors. Licensee MDPI, Basel, Switzerland. This article is an open access article distributed under the terms and conditions of the Creative Commons Attribution (CC BY) license (http://creativecommons.org/licenses/by/4.0/). 